\title{
Sulfated Steroids as Natural Ligands of Mouse Pheromone- Sensing Neurons
}

\author{
Francesco Nodari, ${ }^{1}$ Fong-Fu Hsu, ${ }^{2}$ Xiaoyan Fu, ${ }^{1}$ Terrence F. Holekamp, ${ }^{1}$ Lung-Fa Kao, ${ }^{3}$ John Turk, ${ }^{2}$ and \\ Timothy E. Holy ${ }^{1}$ \\ Departments of ${ }^{1}$ Anatomy and Neurobiology and ${ }^{2}$ Internal Medicine, School of Medicine, Washington University in St. Louis, St. Louis, Missouri 63110, \\ and ${ }^{3}$ Department of Chemistry, Washington University in St. Louis, St. Louis, Missouri 63130
}

\begin{abstract}
Among mice, pheromones and other social odor cues convey information about sex, social status, and identity; however, the molecular nature of these cues is essentially unknown. To identify these cues, we screened chromatographic fractions of female mouse urine for their ability to cause reproducible firing rate increases in the pheromone-detecting vomeronasal sensory neurons (VSNs) using multielectrode array (MEA) recording. Active compounds were found to be remarkably homogenous in their basic properties, with most being of low molecular weight, moderate hydrophobicity, low volatility, and possessing a negative electric charge. Purification and structural analysis of active compounds revealed multiple sulfated steroids, of which two were identified as sulfated glucocorticoids, including corticosterone 21-sulfate. Sulfatase-treated urine extracts lost $>80 \%$ of their activity, indicating that sulfated compounds are the predominant VSN ligands in female mouse urine. As measured by MEA recording, a collection of 31 synthetic sulfated steroids triggered responses 30 -fold more frequently than did a similarly sized stimulus set containing the majority of all previously reported VSN ligands. Collectively, VSNs detected all major classes of sulfated steroids, but individual neurons were sensitive to small variations in chemical structure. VSNs from both males and females detected sulfated steroids, but knock-outs for the sensory transduction channel TRPC2 did not detect these compounds. Urine concentrations of the two sulfated glucocorticoids increased many fold in stressed animals, indicating that information about physiological status is encoded by the urine concentration of particular sulfated steroids. These results provide an unprecedented characterization of the signals available for chemical communication among mice.
\end{abstract}

Key words: vomeronasal; olfactory; glucocorticoids; stress; tuning; multielectrode array

\section{Introduction}

For many mammals, olfactory sensations derive from at least two anatomically and molecularly distinct neural pathways, the main and accessory olfactory systems. In both systems, the initial detection of chemical cues is performed by receptor neurons located in the nasal cavity: receptor cells of the main olfactory system reside in the main olfactory epithelium, and those of the accessory olfactory system reside in the vomeronasal organ (VNO). For both systems, each sensory neuron expresses one or a few types of G-protein-coupled receptors chosen from large receptor families (Firestein, 2001). In mouse, the receptors ex-

\footnotetext{
Received April 3, 2008; revised May 2, 2008; accepted May 5, 2008.

This work was supported by United States Public Health Service Grants R01-DC005964 (T.E.H.), P41-RR00954 (J.T.), P60-DK20579 (J.T.), P30-DK56341 (J.T.), and R37-DK34388 (J.T.) and by the Pew Scholars Program (T.E.H.), We thank Nancy Baenziger for the HPLC apparatus, thin-layer chromatography plates, other chromatography equipment, and advice on purification. Zhongsheng Guo wrote acquisition and some analysis software. Jan Crowley measured HPLC retention times. We thank Alan Bohrer for advice on extraction, Ben Kolber and Louis Muglia for advice on the restraint stress paradigm, Kazu Touhara and his laboratory for ESP1 and recombinant MUP1, Norman Holy, Douglas Covey, and Louis Muglia for discussions, and Nancy Baenziger, Peter Lukasiewicz, Paul Taghert, and Russ Van Gelder for comments on this manuscript. Author contributions are as follows: design of experiments, F.N. T.E.H., and J.T.; sample preparation, F.N., T.F.H., and X.F.; electrophysiology, F.N.; behavior, F.N.; MS, F-F.H., F.N., and X.F.; data analysis, F.N., F.-F.H., T.E.H., and J.T.; and manuscript, F.N. and T.E.H.

The authors declare no competing financial interests.

Correspondence should be addressed to Timothy E. Holy, 660 South Euclid Avenue, Campus Box 8108, St. Louis, M0 63110. E-mail: holy@wustl.edu.

D0I:10.1523/JNEUROSCI.1425-08.2008

Copyright $\odot 2008$ Society for Neuroscience $\quad$ 0270-6474/08/286407-12\$15.00/0
}

pressed by vomeronasal sensory neurons (VSNs) fall in two distinct families, V1R and V2R, which together comprise $\sim 250$ members (Dulac and Torello, 2003; Halpern and MartínezMarcos, 2003; Shi and Zhang, 2007).

The main olfactory system detects volatiles and has an essential role in diverse behaviors that range from foraging (Brunet et al., 1996) to social communication (Hudson and Distel, 1986; Schaal et al., 2003; Lin et al., 2005). In contrast, the accessory olfactory system appears to be more narrowly specialized for social communication, because compromising the VNO leads specifically to deficits in numerous territorial and reproductive behaviors (Wysocki and Lepri, 1991; Leypold et al., 2002; Stowers et al., 2002; Halpern and Martínez-Marcos, 2003; Kimchi et al., 2007).

Although there are many known ligands for main olfactory receptor neurons, our understanding of the natural ligands for VSNs is woefully incomplete. Behaviorally, the best characterized source of VSN ligands is urine. Among known or suspected constituents of urine, a few volatiles (Leinders-Zufall et al., 2000) as well as major histocompatibility complex peptide ligands (Leinders-Zufall et al., 2004) and major urinary proteins (MUPs) (Chamero et al., 2007) have been reported to stimulate VSNs. However, together, at saturating concentrations, these molecular species are reported to excite fewer than $15 \%$ of the neurons in the VNO, well short of the $30-40 \%$ of the neural population 
stimulated by hundred-fold diluted urine (Holy et al., 2000). The specificity of the latter responses to urine is demonstrated by the sex selectivity of individual VSNs and by their dependence on a signal transduction cascade involving phospholipase $\mathrm{C}$ and the ion channel TRPC2 (Holy et al., 2000; Leypold et al., 2002; Stowers et al., 2002). Consequently, this comparison indicates that the source of most of the activity in dilute urine resides in compounds that have not yet been identified.

To learn more about the identity of the compounds detected by VSNs, we therefore undertook a de novo screen of active constituents of urine. Some previous studies used a behavioral screen, sometimes supplemented by comparative chemical analysis of urine from physiologically different animals (Novotny et al., 1986; Jemiolo et al., 1989; Chamero et al., 2007). However, behavior can depend on a blend of pheromones (Wyatt, 2003), making it difficult to obtain functional data from intermediate fractions of a purification. Consequently, we instead used a direct screen, presenting chromatographic fractions of urine to VSNs and recording their neuronal firing responses. We identified a large family of compounds that collectively accounts for much of the activity in female mouse urine.

\section{Materials and Methods}

Urine collection. Thirty BALB/c female mice were housed ( $12 \mathrm{~h}$ light/dark cycle) in six cages with a metal grid bottom suspended several feet above a tub of liquid nitrogen. Frozen voided urine was collected, pooled, and stored at $-80^{\circ} \mathrm{C}$. One liter of female mouse urine was collected by pooling voided urine from these mice over a period of 2 months. Urine was also collected from BALB/c males (four mice) using similar procedures. For Figure $7 A$, urine was collected from age-matched males and females of the strain BALB/c. The animals were generally $6-12$ weeks old, but not older than 5 months, during urine production. Pooled urine was thawed and clarified by filtration using Durapore $47 \mathrm{~mm}$ polyvinylidenefluoride filters (Millipore) having pore diameters of 5, 0.65, 0.45, and $0.22 \mu \mathrm{m}$. All the animals for urine collection and electrophysiological recordings were from The Jackson Laboratory. All experimental protocols followed the United States Animal Welfare Acts and National Institutes of Health guidelines and were approved by the Washington University Animal Care and Use Committee.

Chromatographic methods. Size-exclusion columns were PD-10 or HiTrap $(5 \mathrm{ml})$ (GE Healthcare). Chloroform extraction was performed following the Bligh and Dyer method, without adding acid; urine, chloroform, and methanol were added in the same amount. Octadecyl-silica cartridge (ODS) solid-phase extraction (SPE) used Sep-Pak (2 g) (Waters). The equivalent of $20 \mathrm{ml}$ of urine was loaded on each column, followed by a washing step with $20 \%$ methanol $/ 2 \%$ acetic acid, and final elution with methanol. AG50 resin (strong cation exchange) was from Bio-Rad; $5.6 \mathrm{~g}$ of resin was used for $21 \mathrm{ml}$ equivalent of urine, with a water wash and elution with $6 \mathrm{~N}$ ammonium hydroxide. AG1 resin (strong anion exchange) was from Bio-Rad; $5.25 \mathrm{~g}$ of resin was used for $21 \mathrm{ml}$ equivalent of urine, with $1 \mathrm{~m}$ sodium chloride wash and elution with $1 \mathrm{M}$ sodium chloride in $65 \%$ methanol. Fractions obtained from the ion exchange columns were buffered and then desalted using ODS SPE. WAX columns (weak anion exchange) $(6 \mathrm{cc})$ were from Waters; the equivalent of $20 \mathrm{ml}$ urine was loaded in $10 \%$ methanol $/ 2 \%$ acetic acid, with a wash with $2 \%$ acetic acid in methanol and elution with $5 \%$ ammonium hydroxide in methanol.

HPLC was performed using two Waters 501 pumps, a Waters WISP 712 autosampler, and a Lambda max UV detector. Two ODS columns were used in HPLC: a Waters semiprep ODS Sunfire, silica based, $250 \times$ $10 \mathrm{~mm}, 5 \mu \mathrm{m}$, and an Alltech ODS, silica based, $250 \times 4.6 \mathrm{~mm}, 5 \mu \mathrm{m}$. HPLC fractions were collected every minute. In Figure $2 A$, the Sunfire column was used at $5 \mathrm{ml} / \mathrm{min}$; the loaded sample was $120 \mathrm{ml}$ of WAXurine extract (purified from $391 \mathrm{ml}$ of urine) at 10\% methanol. Purification used a water/methanol gradient, with methanol concentration increasing from 10 to $90 \%$ over $100 \mathrm{~min}$, followed by $90 \%$ for $30 \mathrm{~min}$. For physiology, these fractions were delivered at twofold dilution relative to the original urine sample. For Figure 2, $B$ and $D$, the first cluster (see Fig. $2 A$ ) was repurified with the Alltech column at $1 \mathrm{ml} / \mathrm{min}$. The equivalent of $192 \mathrm{ml}$ of urine was used, with a methanol gradient of $10-58 \%$ in 100 min and then $90 \%$ for $20 \mathrm{~min}$. For physiology, these fractions were supplied at the equivalent of 10 -fold dilution. Fractions in Figure $2 E$ were repurified using a $10-90 \%$ methanol gradient.

Thin-layer chromatography was performed (glass support plate with silica gel 60 matrix, particle size of 5-17 $\mu \mathrm{m}$, layer thickness of $250 \mu \mathrm{m}$, with fluorescent indicator; Sigma) on WAX-urine extracts and developed at room temperature in a saturated $\mathrm{N}$-chamber by the ascending technique. The mobile phase system was chloroform/methanol/water in ratios of 14:6:1. Compounds appeared as dark blue spots on a light green background under UV light. WAX-urine extract in the equivalent of 0.4 $\mathrm{ml}$ of urine was spotted.

Reagents and solutions. Corticosterone 21-sulfate (cort21S) was from Sigma and Steraloids. All the other synthetic sulfated steroids were from Steraloids. They were dissolved in either DMSO or methanol before physiology. SS425 [sulfated steroid 425, a sulfated steroid with mass-tocharge ratio $(\mathrm{m} / \mathrm{z})$ of 425 ] was repurified by HPLC before physiological comparison with synthetic cort21S (see Fig. 4). Recombinant ESP1 and recombinant MUP1 (rMUP1) were from the Touhara Laboratory and dissolved in Ringer's solution. AAPDNRETF, SYFPEITHI, and EEARSM (in PBS) were synthesized by Sigma. Acetic acid, propionic acid, butyric acid, isobutyric acid, isovaleric acid, arginine, methionine, and glutamate were from Sigma and dissolved in PBS. Butanone, pentyl acetate, 2-heptanone, 2,5-dimethylpyrazine, isobutylamine, indole, $p$-cresol, eucalyptol, fenchone, borneol, isoborneol, butyrophenone, ethyl acetate, ethyl propionate, and dimethyl disulfide were from Sigma. Aubepine and ethyl vanilline were from City Chemical. Patchone and phenafleur were from IFF. Muscone was from Firmenich. Farnesenes were from Bedoukian. All these compounds were dissolved in methanol. Sulfatase from Helix pomatia (Sigma) was used in a buffer of $0.23 \mathrm{M}$ sodium acetate, $\mathrm{pH} 5$, at $37^{\circ} \mathrm{C} ; \beta$-glucuronidase VIIA from Escherichia coli (Sigma) was used in a $0.075 \mathrm{M}$ potassium phosphate buffer, $1 \% \mathrm{BSA}, \mathrm{pH} 6.8$, at $37^{\circ} \mathrm{C}$. In both cases, the substrate consisted of the equivalent of $1.5 \mathrm{ml}$ (at $10 \times$ concentration) of ODS- urine extract. Enzymes were used at $1000 \mathrm{U}$ enzyme $/ \mathrm{ml}$ urine, $8.5 \mathrm{ml}$ total reaction volume, for $24 \mathrm{~h}$ at $37^{\circ} \mathrm{C}$. Reacted product was centrifuged at $2000 \times \mathrm{g}$ for $10 \mathrm{~min}$, and the supernatant was subjected to ODS SPE. Ringer's solution consisted of $115 \mathrm{~mm}$ sodium chloride, $5 \mathrm{~mm}$ potassium chloride, $2 \mathrm{~mm}$ calcium chloride, $2 \mathrm{~mm}$ magnesium chloride, $25 \mathrm{~mm}$ sodium bicarbonate, $10 \mathrm{~mm}$ HEPES, and $10 \mathrm{~mm}$ D-(+)-glucose, equilibrated by bubbling with $95 \% \mathrm{O}_{2} / 5 \% \mathrm{CO}_{2}$.

Concentration of SS425 in ODS-urine extract. Mixtures of cort $21 S$ and two other synthetic sulfated steroids (4-pregnen-17,20 $\beta$-diol-3-one sulfate and 4-pregnen-11 $\beta, 17,21$-triol-3,20-dione 21-sulfate) were injected in a TSQ triple quadrupole mass spectrometer to obtain the precursor ion spectra for $\mathrm{m} / \mathrm{z} 97$ and 81 . Calibration curves were obtained from the calculated and the measured ratio of cort $21 \mathrm{~S}$ with each of the other two standards for several different concentrations of cort $21 \mathrm{~S}$. The calibration standards were added to ODS-urine extract and precursor ion measured. The calibration curves were then used to calculate the concentration of SS425.

Electrophysiological recordings. Intact vomeronasal epithelia were isolated and mounted on a multilelectrode array as described previously (Holy et al., 2000): briefly, the vomeronasal epithelium was removed from the bony capsule, and the neuroepithelium was mechanically dissected as an intact sheet from the basal lamina. It was then held in place on the electrode array using a nylon mesh. The recorded cell types, in terms of specific receptor expressed, would be expected to vary from experiment to experiment. Male mice of the B6D2F1 strain were used in most experiments: all figures result from experiments with male B6D2F1 mice, and, except for Table 1, VNOs from BALB/c females were used only for experiments that revealed the activity of compounds with $\mathrm{m} / \mathrm{z} 428$ and 437. The compounds listed in Table 1 were tested on vomeronasal epithelia dissected from wild-type males and females of the B6D2F1 strain and from $\operatorname{trpc} 2^{-1-}$ males (Stowers et al., 2002). The animals were between 6 weeks and 5 months old. Different preparations mean different VNOs from different subjects.

Urine, its fractions, and synthetic compounds were diluted with Ring- 
A

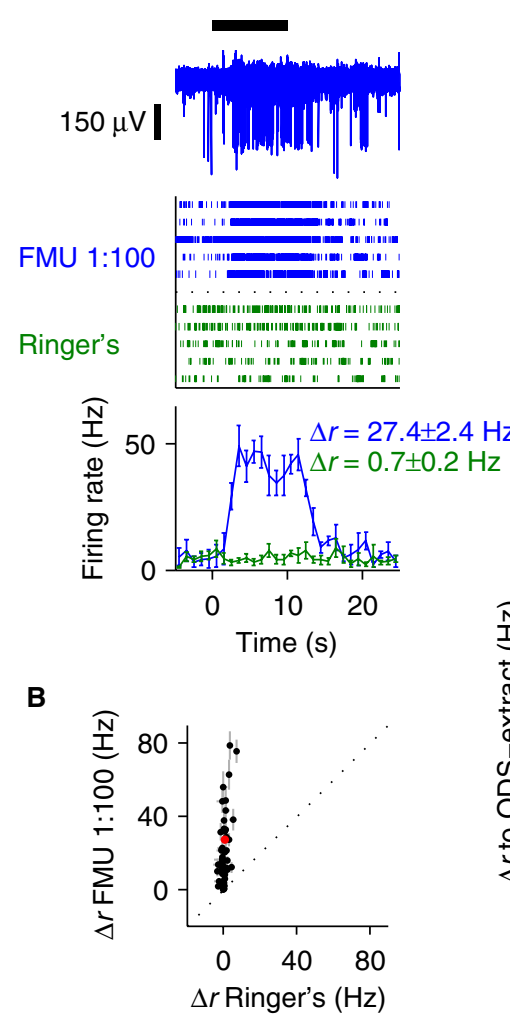

C

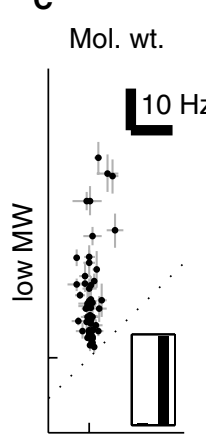

high MW
D

Polarity

E

ODS

FationX

G

AnionX

H

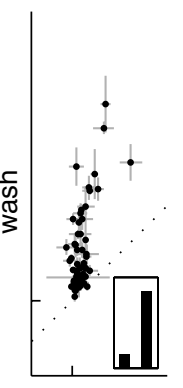

elution

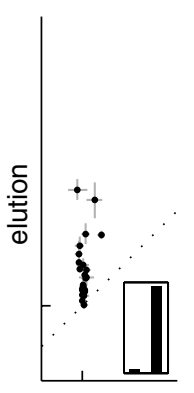

wash

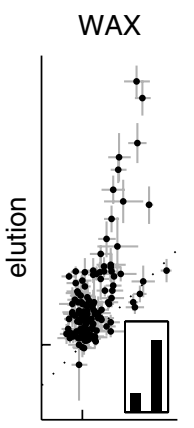

wash

I
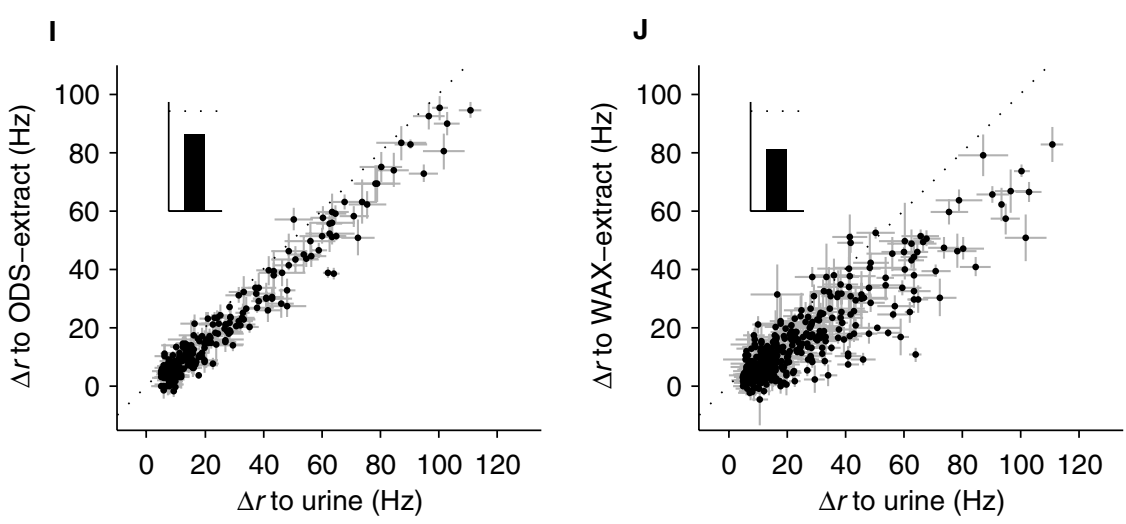

Figure 1. Physicochemical properties of active compounds. $A$, Extracellular recording from the vomeronasal epithelium. The voltage signal recorded from a representative electrode is illustrated. The black bar represents the timing of the stimulus application. Raster plots represent each spike as a vertical tick mark. The six rows represent six interleaved presentations of diluted female mouse urine (FMU, blue) or a Ringer's solution control (green). The panel on the bottom plots the average firing rate across six repeats in $1 \mathrm{~s}$ bins. Error bars indicate SEM across trials. The firing rate change, $\Delta r$, and its SEM for the urine stimulus and the Ringer's solution control are shown. Note the increase in firing rate during the presentation of diluted urine but not Ringer's solution control. $\boldsymbol{B}$, The response on each electrode can be summarized by plotting its $\Delta r$ in response to 1:100 female mouse urine versus its $\Delta r$ for Ringer's solution control. Each electrode in a single preparation is represented by a point; the electrode in $\boldsymbol{A}$ is marked in red. $\mathbf{C}-\boldsymbol{H}$, Physiological testing of the fractions obtained after each purification step. Each panel represents the response (measured by $\Delta r$ ) of electrodes to both of the fractions resulting from binary purification. Insets show overall percentage of activity excited by the stimulus on the horizontal (first bar) or vertical (second bar) axis. Firing rate scale bars in Capply to $\boldsymbol{C}-\boldsymbol{H}$. The single tick along each axis marks $\Delta r=0$. Error bars are SEM. C, Desalting column, 56 responsive (see Materials and Methods) electrodes from 3 preparations: $\boldsymbol{D}$, chloroform extraction, 59 responsive electrodes from 3 preparations; $\boldsymbol{E}$, ODS solid-phase extraction, 19 electrodes from 2 preparations; $\boldsymbol{F}$, strong cation exchange, 58 electrodes from 3 preparations; $\boldsymbol{G}$, strong anion exchange, 25 electrodes from 5 preparations; $\boldsymbol{H}$, weak anion exchange, 138 electrodes from 6 preparations. $\boldsymbol{I}$, Urine subjected sequentially to the purification steps in $\boldsymbol{D}$ and $\boldsymbol{E}$ does not lose physiological activity: 241 electrodes from 9 preparations. Inset, Percentage of overall activity retained by extract (100\% indicated by dotted line). $J$, Urine subjected sequentially to the purification steps in $\boldsymbol{D}, \boldsymbol{E}$, and $\boldsymbol{H}$ retains most of its activity: 421 electrodes from 14 preparations. Inset is as in $\boldsymbol{I}$.

er's solution immediately before the dissection and recording session. Residual methanol or DMSO concentration in the stimulus solution was never higher than $0.1 \%$. All experiments included at least one negative control (Ringer's solution) stimulus tube. In some experiments, stimuli were stored in syringes under helium pressure and dispensed through opening of valves (Automate Scientific); in most cases, we used an HPLC pump (Gilson 307) and a robotic liquid handler (Gilson 215) capable of taking samples from prepared tubes and injecting them in an HPLC valve (Gilson 819 injection module). This robot was controlled by the Gilson 735 software. With both stimulus delivery apparata, continuously bubbled Ringer's solution alternated with stimuli to produce continuous flow over the epithelium. The timing of stimulus delivery (valve opening and closing for the Automate apparatus; HPLC valve switch for the Gilson apparatus) was monitored electrically and fed back to the acquisition software. Stimuli were presented in sequence, and the sequence was repeated four to seven times; the exception was Figure $2 \mathrm{~A}$, for which there were only two repeats because of the large number of different stimuli tested.

Extracellular recording was performed using multielectrode planar arrays (ALA Scientific Instruments) $(10 \mu \mathrm{m}$ flat titanium nitride electrodes isolated with silicon nitride) in one of two configurations: a lowdensity configuration, in which 60 electrodes were in a grid of $8 \times 8,100$ $\mu \mathrm{m}$ apart; and a high-density configuration, in which electrodes were 30 $\mu \mathrm{m}$ apart, in two fields of $6 \times 5$ electrodes each. Electrical signals were amplified with an MEA 1060 amplifier (ALA Scientific Instruments), acquired at $10 \mathrm{KHz}$ with a data acquisition card (National Instruments), and saved to disk. We used custom data acquisition and data analysis software based on COMEDI (http://www.comedi.org) and Matlab (MathWorks).

Data analysis. $\Delta r$ was calculated using time windows of $5 \mathrm{~s}$ before stimulus application and $15 \mathrm{~s}$ after stimulus onset, with stimulus pulses lasting $10 \mathrm{~s}$. Mean and SEM were calculated across repeated trials of the same stimulus for the given electrode. Firing-rate scatter plots (see Figs. $1 C-J, 5 B, C)$ show only electrodes that recorded responses to 100 -fold dilute urine with $\Delta r>5 \mathrm{~Hz}$; in these plots, the concentration of all the stimuli were the equivalent of 100 -fold dilute urine. Scatter plots in Figure $5 D-I$ show all recorded electrodes.

In quantifying the percentage retained in binary purification steps (see Fig. $1 C-H$ ), a summed $\Delta r$ to each of the two fractions, $\Delta r_{\mathrm{A}}$ and $\Delta r_{\mathrm{B}}$, was calculated across all responsive electrodes. The amount retained was the larger of $\Delta r_{\mathrm{A}}$ and $\Delta r_{\mathrm{B}}$ divided by their sum, quoted as a percentage.

For Figure $6 B$, the normalized response $\rho_{i}$ to the $i$ th stimulus was calculated as the ratio $\rho_{i}=\Delta r_{i} / \max _{j}\left(\Delta r_{j}+\sigma_{j}\right)$, where $\Delta r_{j}$ is the change in firing rate to stimulus $j$ averaged over trials, $\sigma_{j}$ is the SD of $\Delta r$ over trials in response to stimulus $j$, and the maximum is taken over all stimuli for the given neuron. Consequently, $\rho_{i}$ ranges from -1 to 1 , but, because of 
the inclusion of the SD in the denominator, even the most effective stimulus of the neuron must lead to firing rate changes that well exceed the variability across trials if it is to achieve values near \pm 1 . For this panel, the number of different stimuli activating a given cell (see Results) was defined by $\rho_{i}>0.3$. For Figure $2 A$, the same procedure was used, except $\sigma_{j}$ was replaced by the SD to Ringer's solution (HPLC fraction were tested in only two trials, Ringer's solution in five trials).

For Table 1, responsiveness was defined as exceeding $\Delta r>5 \mathrm{~Hz}$ and being distinguishable from the response to the Ringer's solution negative control at a level of $p<0.01$ using a ranksum test. Satisfying this rank-sum criterion requires a minimum of five trials, and, in a fivetrial experiment, it can only be satisfied if the response to the compound was higher than the response to the Ringer's solution control in all five trials. For Figure $6 F$, one of the three preparations used four trials, so a threshold of $\Delta r>$ $5 \mathrm{~Hz}$ and $p<0.05$ was used.

The statistical comparison between responses by VNOs isolated from males and females and from wild-type and $\operatorname{trpc} 2^{-/-}$animals was performed as a bootstrap analysis. First, the total number of responsive electrodes for preparations using tissue from the same sex or genotype was calculated (of preparations using all 30 sulfated steroids in Table 1, there were two male, four female, and two $\operatorname{trpc} 2^{-/-}$preparations; Table 1 also includes additional preparations that used a smaller complement of stimuli, but these preparations were not included in the bootstrap analysis). Then, the number of electrodes showing responses $(p<0.01$ and $\Delta r>5 \mathrm{~Hz}$ ) to each synthetic sulfated steroid was calculated, yielding the percentage $p_{i}$ of electrodes that responded to stimulus $i$, averaged across preparations with tissue from the same sex. As a measure of the difference $D$ between males and females, we calculated the difference in these percentages and then summed their absolute value across all stimuli,

$$
D=\sum_{i} \mid p_{i}(\text { male })-p_{i}(\text { female }) \mid
$$

To determine the statistical significance of this difference, we compared this true difference with the values $D_{j}^{\prime}$ obtained by randomly scrambling the sexes of the animals. This scrambling was performed 1000 times, yielding 1000 different $D_{j}^{\prime}$. For male-female comparisons, the true difference was found to be typical (ranking 451 of 1000 bootstrap realizations) and thus was not significantly correlated to the sex of the experimental animals. The analysis for $\operatorname{trpc} 2$ knock-outs was performed in the same manner, pooling both males and females of wild-type mice. In this case, the true genotype assignment produced the least typical of all possible assignments (rank 1 of 28 unique assignments).

When single units were isolated from data taken with the highdensity arrays (see Figs. $4 B, C, 6 C-I$ ), each field was treated as a "30-trode," and spikes were sorted by waveform shape across all electrodes (Segev et al., 2004). When they were isolated from data taken with the low-density arrays (see Fig. $6 \mathrm{~A}, \mathrm{~B}$ ), only the spike waveform recorded by individual electrodes was used. Single units were identified by having a well isolated cluster of spike waveforms. Reported single units had clean refractory periods, typically of $\sim 25 \mathrm{~ms}$.

Stress-restraint behavior. Fifteen 7-week-old female mice of the $\mathrm{BALB} / \mathrm{c}$ strain were used. They were housed in three cages, five animals per cage. Two trials were conducted on two different days. For each trial, one cage was used for the control animals and another cage contained the animals subjected to stress. The animals subjected to stress were different in the two trials. Urine was collected as described for $4 \mathrm{~h}$, during the dark cycle of their subjective day. In the middle of the subjective day, five animals were subjected to restraint stress (Boyle et al., 2006) for $15 \mathrm{~min}$; the control group was not handled. Urine collection then proceeded for an additional $4 \mathrm{~h}$. The resulting collected urines were prestress (prs), poststress (pos), precontrol (prc), and postcontrol (poc). $m / z 425,427$, and 429 were measured by precursor ion mass spectrometry (MS) in each fraction. Their change was measured as (pos/prs)/(poc/prc).

\section{Results}

\section{Strategy for physiological recording}

Because VSNs express only one or a few of the large number ( $\sim 250)$ of receptor types (Dulac and Torello, 2003; Halpern and Martínez-Marcos, 2003), one might expect that different neurons would be sensitive to different ligands (Leinders-Zufall et al., 2000). To cope with this anticipated diversity, we used a planar array of 60 extracellular microelectrodes (Holy et al., 2000) to record sensory responses of large numbers of VSNs simultaneously in the isolated vomeronasal neuroepithelium. Each electrode was capable of detecting the spiking activity of one or a few neurons (Fig. 1A). Here we present data from a total of 57 preparations, from which stimulus responses were typically recorded to 100-300 individual stimulus presentations delivered over a period of several hours. Typically, spiking activity was recorded on 30-40 electrodes for each preparation, which yielded a total of $\sim 2000$ active recording sites. Stimuli consisted of urine, or its chromatographic fractions, from females of the BALB/c strain of mice. Stimuli were diluted to their final concentrations with Ringer's solution and applied to the sensory epithelia in cycles, with different stimuli interleaved over multiple repeated presen- 
A

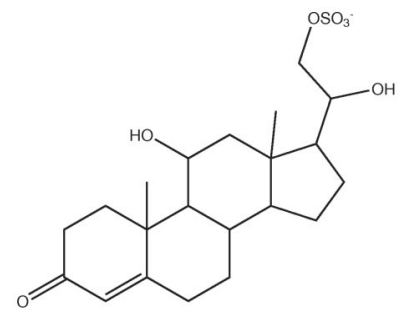

B

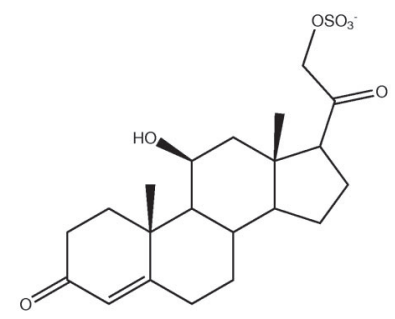

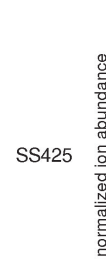
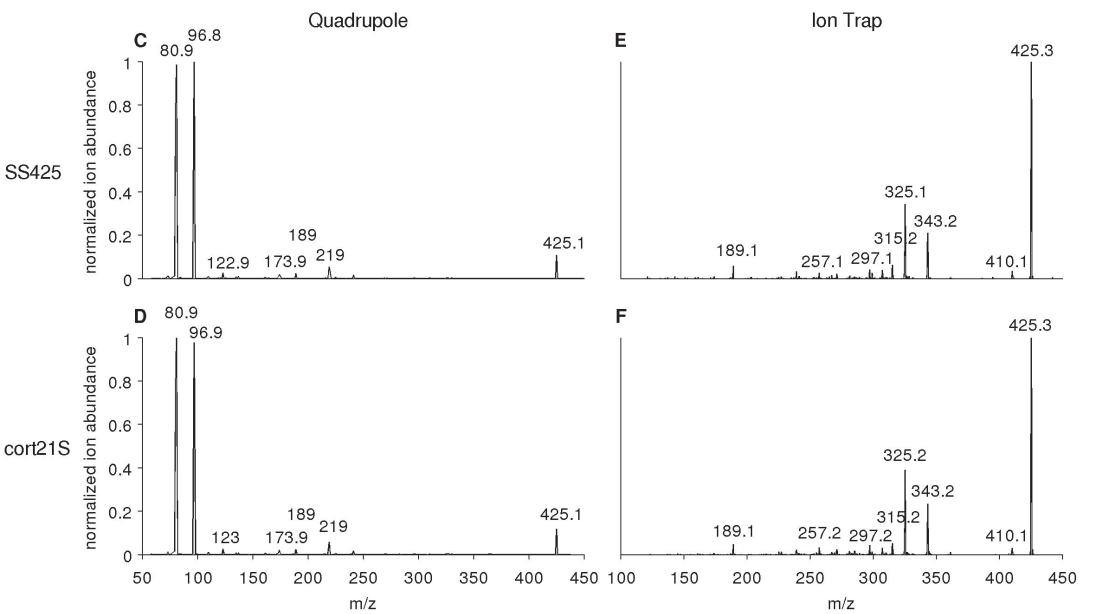

Figure 3. Structures of SS427 and cort21S and identity of SS425 and cort21S by mass spectrometry. A, Structure of SS427. B Structure of corticosterone 21-sulfate. $\mathbf{C}-\boldsymbol{F}$, Mass spectrometry of cort21S and SS425 reveals identical fragmentation patterns with two different instruments. $C, D, A$ triple quadrupole instrument was used, and identical fragments were observed for $S S 425$ $(\boldsymbol{C})$ and cort21S (D). $\boldsymbol{E}, \boldsymbol{F}$, An ion trap instrument was used, and identical fragments were observed for $S S 425(\boldsymbol{E})$ and cort21S $(\boldsymbol{F})$.

tations. Multiunit activity from each electrode was recorded, and the response on a single electrode to any given stimulus was summarized as the firing rate change $\Delta r$, calculated as the average firing rate on stimulation minus the average firing rate before stimulation (Fig. 1 $A, B$ ) (see Materials and Methods).

\section{Physicochemical properties of VSNs ligands}

Given that urine is expected to contain many inactive compounds, we first tested a number of binary purification steps to create extracts enriched in just the active compounds. Because each electrode records from a particular group of neurons and different neurons could be activated by different ligands, the consequences of a given binary purification are best assessed in terms of activity recorded on individual electrodes (Fig. $1 C-H$ ). However, a simple overall measure of activity can be obtained by calculating the percentage of aggregate $\Delta r$, summed across all electrodes, present in the more active of the two fractions (see Materials and Methods). This initial screen revealed that most of the activity was attributable to compounds of $<5 \mathrm{kDa}$ molecular weight when separated by size exclusion chromatography (Fig. $1 C, 97 \%$ of aggregate $\Delta r$, inset) that remained in the polar layer in a chloroform/methanol/water partition (Fig. $1 D, 84 \%$ ), bound to an ODS (Fig. 1E, 95\%), did not bind to a strong cation exchange resin (Fig. $1 F, 85 \%$ ) but did bind to a strong anion exchange resin (Fig. 1G, 96\%) and remained bound to a WAX column even after a 95\% methanol, $\mathrm{pH} \approx 5$ wash (Fig. $1 \mathrm{H}, 80 \%$ ). These findings indicated that most of the activity could be attributed to compounds with unexpectedly homogeneous physicochemical properties.

Extracts were prepared by sequential use of chloroform/methanol/water liquid-liquid extraction, ODS binding (designated
ODS- urine extract), and (in most cases) WAX binding (designated WAX-urine extract). The resulting extracts retained most of the activity of the original sample (Fig. 1I,J; ODS- urine extract, 77\%, inset; WAX-urine extract, $62 \%$, averaged across electrodes). This percentage of retained activity was quite consistent across different recorded preparations [ODS extract, $72 \pm 11$ (mean \pm SD) across 9 preparations; WAX, $61 \pm 15$ across 14 preparations], indicating that the sampling of different neuronal types by the multielectrode array was reproducible and perhaps fairly comprehensive. The active compounds were also relatively involatile, because activity persisted after evaporating the organic solvent to dryness and reconstituting with aqueous solutions (Fig. $1 D-J$; in particular, I compares evaporated and reconstituted ODS extract against the original urine sample, with $77 \%$ of activity surviving the sum total of all purification steps including evaporation). This result is consistent with behavioral experiments indicating that direct contact with the stimulus is required for most $\mathrm{VNO}$-mediated behaviors (Brennan and Kendrick, 2006).

\section{Isolation of multiple active compounds by HPLC}

Starting from 11 of BALB/c female mouse urine, the final WAX-urine extract was further fractionated by HPLC using an ODS column and a water/methanol gradient solvent system. Physiological assay of the resulting fractions revealed at least two prominent clusters of activity (Fig. 2A). The first of these clusters eluted at 42-46\% methanol and was subjected to a second HPLC purification, resulting in many new "subfractions" that collectively contained numerous distinct compounds, for additional study. Individual subfractions were analyzed using electrospray ionization (ESI) MS in the negativeion mode (because active compounds, from their binding properties, were expected to be anionic in liquid solution). Analysis of one active subfraction revealed a single predominant ion with an $\mathrm{m} / z 427$ (hereafter designated as SS427) (Fig. 2B, C). In other cases, the subfractions contained multiple compounds. Nevertheless, because individual compounds were distributed across several consecutive subfractions, the concentration profile across subfractions could be correlated with the physiological response profile measured on individual electrodes. In this way, we obtained evidence for activity attributable to compounds with $\mathrm{m} / \mathrm{z}$ values of 425 (Fig. 2D), 428, 429 (Fig. 2 E), 437, and 441 (hereafter designated as SS425, SS428, SS429, SS437, and SS441, respectively).

\section{Structural characterization of active compounds}

SS427 was characterized further using collisionally activated dissociation (CAD) and tandem mass spectrometry (MS/MS) with high (exact) resolution and by proton and carbon nuclear magnetic resonance (two-dimensional correlation spectroscopy, total correlation spectroscopy, and heteronuclear multiple quantum coherence) as will be described in a separate publication. These analyses revealed this compound to be the sulfated steroid 
4-pregnene-11,20,21-triol-3-one 21-sulfate (Fig. 3A). A synthetic standard of SS427 is not available and was therefore not tested directly against purified SS427.

However, this structural determination suggested that other active compounds might also be sulfated steroids. A commercially available standard compound, cort $21 S$ (Fig. $3 B$ ), would be expected to produce an $[\mathrm{M}-\mathrm{H}]^{-}$ion of $m / z 425$, which matched the $\mathrm{m} / \mathrm{z}$ of endogenous SS425. We therefore first determined whether SS425 is identical to cort21S.

Urine-derived SS425 and synthetic cort21S were indistinguishable by thin-layer chromatography and reversed-phase HPLC (data not shown). ESI/MS/MS analyses of SS425 and cort21S revealed identical tandem spectra under two different sets of conditions (Fig. 3C-F). Moreover, physiological testing of both purified SS425 and cort $21 \mathrm{~S}$ revealed that cells responding to cort $21 \mathrm{~S}$ ( 2 of 25 cleanly isolated single units in two preparations) also responded to SS425 with the same concentration dependence (Fig. 4A-C). Together, these results indicate that cort $21 \mathrm{~S}$ is detected by VSNs and is identical to the endogenous ligand SS425.

The identification of two active sulfated steroids (cort21S/ SS425 and SS427), together with our observation that several other active compounds have similar molecular weights and physicochemical properties, suggested that other active compounds might also be sulfated steroids. Tandem mass spectra obtained after CAD of SS428, SS429, and SS437 all exhibited fragmentation patterns characteristic of sulfated steroids (data not shown). To determine whether additional sulfated compounds were present in BALB/c female mouse urine, we examined ODS extracts by precursor ion scanning for compounds that fragmented to produce a sulfate ion $\left(\mathrm{HSO}_{4}{ }^{-}\right.$with $\mathrm{m} / z$ 97) (supplemental Fig. S1 $a$, available at www.jneurosci.org as supplemental material). In addition to confirming the presence of compounds that were identified above in our activity screen (SS425, SS427, SS428, SS429, and SS441), this revealed several other sulfated compounds $(m / z 401,416,431,439,443,445$, and 447) (supplemental Fig. S1 $a$, available at www.jneurosci.org as supplemental material). Thus, BALB female urine contains at least 13 sulfated compounds in the $m / z$ range of $400-450$, at least six of which were identified in our screen as activating VSNs. Of these six, at least five are sulfated steroids.

\section{Sulfated compounds account for the large majority of VSN responses to female mouse urine}

Given the presence of multiple active sulfated steroids, we wondered how much of the activity in female mouse urine is attributable to these compounds. To answer this question, BALB/c female mouse urine was treated with a sulfatase enzyme, which hydrolyzes the sulfate ester bond of a wide variety of substrates. The effectiveness of this digestion was verified by the disappearance of ions in the mass range 390-480 that, by ESI/MS/MS, have sulfate $(m / z 97)$ as a product ion (supplemental Fig. S1 $a$ and inset, available at www.jneurosci.org as supplemental material). Because many sulfatase preparations also possess glucuronidase activity, we also treated urine with glucuronidase (supplemental Fig. S1b-d, available at www.jneurosci.org as supplemental material).

Firing rates recorded on a sample electrode in response to enzymatically digested stimuli are shown in Figure 5A. Compared with the undigested control ( - sulf), the stimulus that was treated with sulfatase ( + sulf) evoked little response. In contrast, treating the stimulus with glucuronidase did not abolish the firing rate increase (+ glucur vs - glucur). This pattern of stimulus/

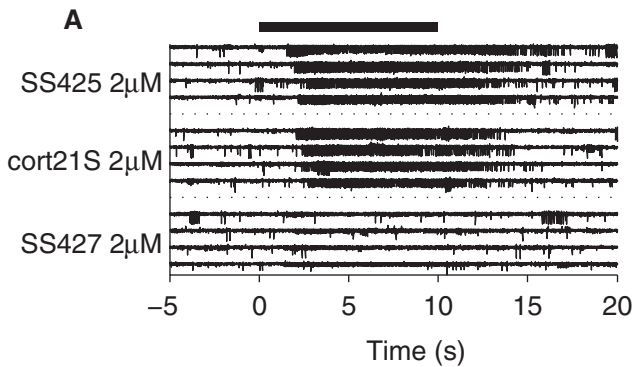

B

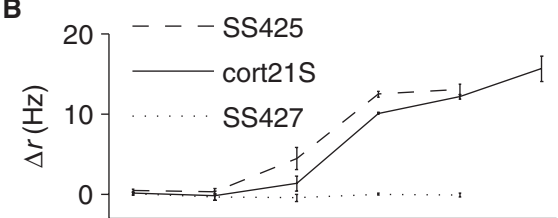

C

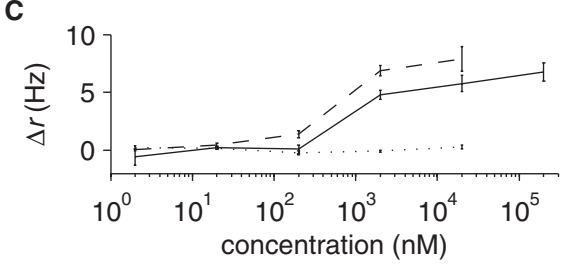

Figure 4. Equivalence of cort21S and $S S 425$ as revealed by neuronal responses. $A$, Raw voltage recordings on one electrode in response to $\$ \$ 425$, cort21S, and $\$ \$ 427$. All four presentations of these stimuli are shown (stimuliare shown grouped by identity but were presented in interleaved manner). Each stimulus was presented at $2 \mu \mathrm{m}$. The black bar represents the stimulus timing. $B, C$, Single-unit responses to a concentration series of SS425, cort21S, and SS427. Note the similarity between the dose/response curves of $S S 425$ and cort21S and their difference with the $S 5427$ curve. Both cort21S-responsive neurons displayed an $\mathrm{EC}_{50}$ between $200 \mathrm{~nm}$ and $2 \mu \mathrm{m}$; the concentration of SS425 in ODS- urine extract was estimated (see Materials and Methods) to be $\sim 1 \mu \mathrm{m}$. Error bars indicate SEM across trials. The neuron in $\boldsymbol{B}$ was recorded on the electrode shown in $\boldsymbol{A}$.

response was common among all the electrodes (Fig. 5B,C). Strikingly, the sample treated with sulfatase lost $81 \%$ (averaged across electrodes) of its physiological activity relative to untreated control (Fig. 5B), demonstrating that most of the activity in urine is sensitive to sulfatase digestion. Although the glucuronidase digestion also resulted in some loss of activity (Fig. 5C, 27\% averaged across electrodes), most of the activity was resistant to digestion by glucuronidase.

When several synthetic compounds were tested physiologically, sulfated steroids were far more active than any other tested compound or peptide (Fig. 5D-I, Table 1). Considering only electrodes that demonstrated responses to at least one of all the stimuli used in a particular experiment, 35 previously reported ligands together accounted for only 7 responses of 5677 electrode/stimulus pairwise tests (Table 1); three of these were attributable to a single ligand, ESP1 (Kimoto et al., 2005, 2007). In contrast, electrode/stimulus pairwise tests involving a panel of 31 sulfated steroids produced responses in 190 of 4882 cases, a percentage $>30$-fold higher than for previously reported ligands. Of 16 preparations using at least eight different sulfated steroids listed in Table 1, a total of 245 electrodes recorded responses to at least one stimulus (including urine and high potassium) in the stimulus set; of these, 82 responded to at least one sulfated steroid. Therefore, the synthetic sulfated steroids used in our experiments collectively activated a substantial percentage of the neurons that could be excited by any stimulus, including urine and high potassium, that we tested. Together, these results indicate that sulfated steroids are the predominant VSN ligands in female 
A
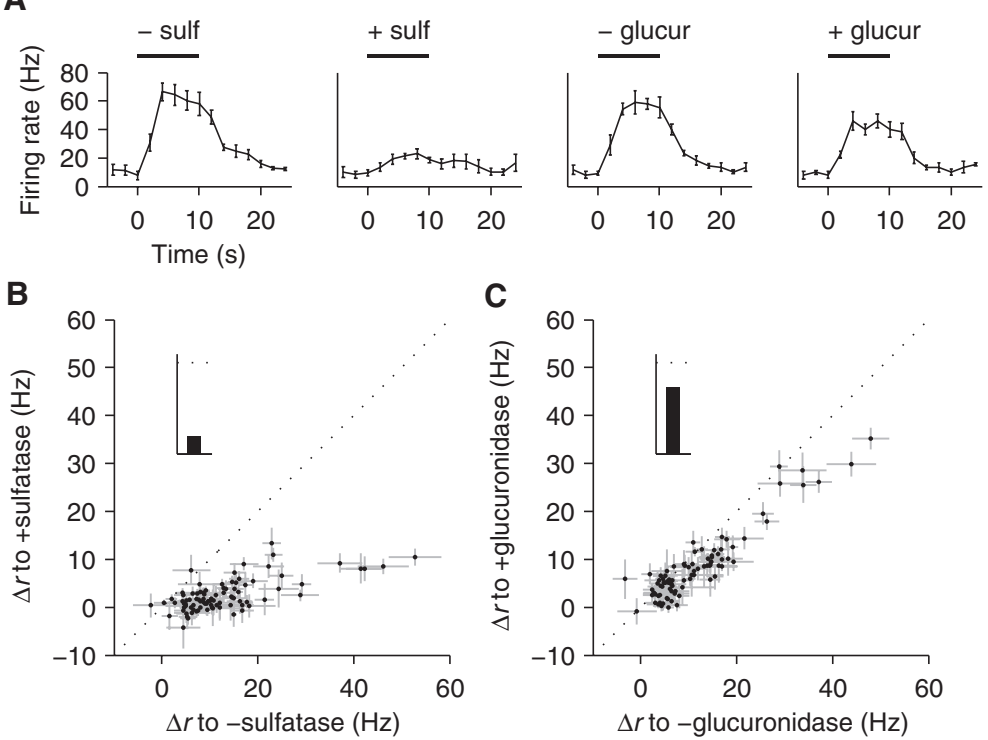

D

E
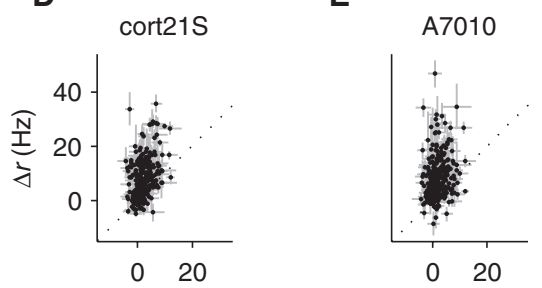

$\mathbf{F}$

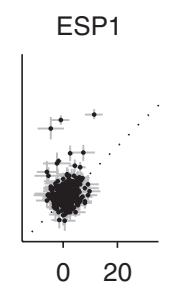

G

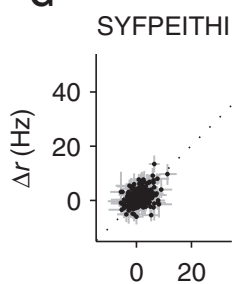

H

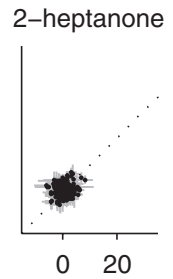

$\Delta r$ to Ringer's $(\mathrm{Hz})$
I

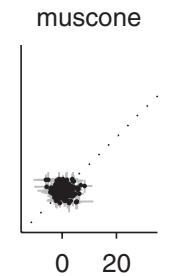

Figure 5. Sulfate conjugates account for a large percentage of $B A L B / c$ female physiological activity and greatly exceed the activity of previously reported VSN ligands. $A$, The firing rates recorded on a sample electrode are shown in response to control and enzymatically digested stimuli. Firing rate increased greatly to urine extracts not treated with sulfatase (-sulf) and to urine extracts treated with glucuronidase ( + glucur) or not treated with glucuronidase ( - glucur). In contrast, treatment with sulfatase ( + sulf) nearly abolished the response. The black bars represent the stimulus timing. $\boldsymbol{B}$, Multiunit activity evoked by sulfatasetreated ODS - urine extract compared against mock-treated extract ( 90 electrodes from 6 preparations), revealing that the majority of activity in urine is sensitive to sulfatase digestion. Inset, Percentage of overall activity retained after digestion. $C$, Multiunit activity evoked by $\beta$-glucuronidase-treated ODS- urine extract compared against mock-treated extract (90 electrodes from 6 preparations), indicating that the majority of activity is resistant to digestion by glucuronidase. $D-I$, Multiunit recordings of neural responses to six compounds: cort21S (D, 360 electrodes, 50 and $100 \mu \mathrm{M})$, A7010 (E, 300 electrodes, 50 and $100 \mu \mathrm{M})$, ESP1 ( $\boldsymbol{F}, 540$ electrodes, $0.1 \mu \mathrm{m}$; these multiunit data included for comparability; a detailed study of the single units isolated from these electrodes was reported by Kimoto et al., 2007), SYFPEITHI ( $G$, 480 electrodes, 0.1 and $1 \mu \mathrm{M}$ ), 2 -heptanone $(\boldsymbol{H}, 540$ electrodes, 100 $\mu \mathrm{M})$, and muscone $(I, 360$ electrodes, $100 \mu \mathrm{M})$. In $\mathbf{D}-\boldsymbol{I}$, all recorded electrodes are shown; the percentage of responsive electrodes is presented in Table 1.

mouse urine and excite an unprecedented amount of activity in VSNs.

\section{VSN responses to sulfated steroids are highly selective}

The presence and activity of many sulfated steroids raises the question of whether individual VSNs are selective for particular ligands. To address this issue, we tested a panel of 31 synthetic compounds collectively spanning the androstan-, androsten-, cholestan-, estratrien-, pregnan-, and pregnen- families of sulfated steroids (supplemental Fig. S2, available at www.jneurosci.org as supplemental material). At concentrations as high as $100 \mu \mathrm{M}$, single VSNs displayed striking selectivity among members of this family (Fig. 6A). Of 12 responsive cleanly isolated single units (Fig. 6B), five responded only to a single compound; the remainder showed clear responses to two to four compounds, but, in all such cases, a given neuron responded only to compounds with close structural similarity (supplemental Fig. S2, available at www.jneurosci.org as supplemental material).

To investigate tuning specificity in finer detail, we also measured responsiveness as a function of concentration. We chose a set of eight close analogs of cort21S and tested concentrations ranging from $50 \mathrm{nM}$ to 50 $\mu \mathrm{M}$. Analogs were chosen to determine whether the sulfate could be replaced by glucuronidate, the importance of sulfate position, the significance of the hydroxyl at $\mathrm{C} 11$, and the requirement for the methyl group attached to C10 (supplemental Fig. S2, available at www.jneurosci.org as supplemental material). Cells that responded to cort21S did not respond to other compounds, and their responses to cort $21 \mathrm{~S}$ showed different thresholds: the neuron in Figure $6 C$ had a detection threshold between 50 and $500 \mathrm{~nm}$, the neuron in Figure $6 D$ had a threshold between $500 \mathrm{~nm}$ and 5 $\mu \mathrm{M}$, and the one in Figure $6 E$ between 5 and $50 \mu \mathrm{M}$. Other neurons responded selectively to A7010 (Fig. 6G), E4105 (Fig. $6 \mathrm{H}$ ), and A6940 (Fig. 6I). One cell responded to both P2135 and P3865, two pregnan-sulfates, but only at the highest concentration tested (Fig. 6J), similar to the concentrations presented in Figure 6, $A$ and $B$.

These responses demonstrate strong selectivity for particular molecular features, although not always to the point of exclusive selectivity for a single compound. Neurons discriminated between the presence and absence of the methyl attached to C10 (A7010 vs E4105) (Fig. $6 G, H)$. Individual VSNs displayed preferences for either member of a pair of stereoisomers (Fig. 6G,I; also cells 1, 4, and 7 in response to $\mathrm{P} 8168$ and $\mathrm{P} 8200$ in $B$ ), whereas other neurons seemed not to have a strong preference (Fig. $6 \mathrm{~B}$, cells 2 and 3 ), at least at a fixed concentration.

VSNs from males and females respond to sulfated steroids

To determine whether sulfated steroids can be detected by both males and females, we recorded from VSNs in epithelia isolated from both sexes. Table 1 shows that both males and females have neurons that respond to sulfated steroids. Furthermore, although the percentage of electrodes activated var- 
Table 1. Responsiveness to synthetic compounds

\begin{tabular}{|c|c|c|c|c|c|c|}
\hline Stimulus & Female & Male & $\operatorname{trpc} 2^{-1-}$ & Female (\%) & Male (\%) & $\operatorname{trpc} 2^{-1-}(\%)$ \\
\hline A0225 & $6 / 42$ & $1 / 64$ & $0 / 21$ & 14.3 & 1.6 & 0 \\
\hline A2398 & $1 / 42$ & $5 / 64$ & $0 / 21$ & 2.4 & 7.8 & 0 \\
\hline$A 2460$ & $4 / 42$ & $2 / 64$ & $0 / 21$ & 9.5 & 3.1 & 0 \\
\hline A2534 (50 $\mu \mathrm{M})$ & $1 / 42$ & $2 / 64$ & $0 / 21$ & 2.4 & 3.1 & 0 \\
\hline A6940 (100 and $50 \mu \mathrm{M})$ & $6 / 42$ & $5 / 182$ & $0 / 21$ & 14.3 & 2.7 & 0 \\
\hline A7010 (100 and $50 \mu \mathrm{m})$ & $5 / 42$ & $7 / 182$ & $0 / 21$ & 11.9 & 3.8 & 0 \\
\hline A7864 & $2 / 42$ & $8 / 64$ & $0 / 21$ & 4.8 & 12.5 & 0 \\
\hline A8530 & $0 / 42$ & $2 / 64$ & $0 / 21$ & 0 & 3.1 & 0 \\
\hline C4385 & $0 / 42$ & $0 / 64$ & $0 / 21$ & 0 & 0 & 0 \\
\hline (5075 (10 $\mu \mathrm{M})$ & $0 / 42$ & $0 / 64$ & $0 / 21$ & 0 & 0 & 0 \\
\hline C6905 (50 $\mu \mathrm{M})$ & $0 / 42$ & $1 / 64$ & $0 / 21$ & 0 & 1.6 & 0 \\
\hline E0588 & $3 / 42$ & $1 / 64$ & $0 / 21$ & 7.1 & 1.6 & 0 \\
\hline E0893 & $0 / 42$ & $2 / 64$ & $0 / 21$ & 0.0 & 3.1 & 0 \\
\hline E1050 & $2 / 42$ & $4 / 64$ & $0 / 21$ & 4.8 & 6.3 & 0 \\
\hline E1100 & $1 / 42$ & $0 / 64$ & $0 / 21$ & 2.4 & 0 & 0 \\
\hline E1103 & $1 / 42$ & $1 / 64$ & $0 / 21$ & 2.4 & 1.6 & 0 \\
\hline E2335 & $0 / 42$ & $0 / 64$ & $0 / 21$ & 0 & 0 & 0 \\
\hline $\mathrm{E} 2732$ & $0 / 42$ & $0 / 64$ & $0 / 21$ & 0 & 0 & 0 \\
\hline $\mathrm{E} 4105(50 \mu \mathrm{M})$ & $3 / 42$ & $5 / 182$ & $0 / 21$ & 7.1 & 2.7 & 0 \\
\hline P2135 (50 $\mu \mathrm{M})$ & $2 / 42$ & $7 / 182$ & $0 / 21$ & 4.8 & 3.8 & 0 \\
\hline P3817 & $9 / 42$ & $11 / 64$ & $0 / 21$ & 21.4 & 17.2 & 0 \\
\hline P3865 (100 and $50 \mu \mathrm{M})$ & $1 / 42$ & $4 / 182$ & $0 / 21$ & 2.4 & 2.2 & 0 \\
\hline P8168 & $4 / 42$ & $2 / 64$ & $0 / 21$ & 9.5 & 3.1 & 0 \\
\hline P8200 & $8 / 42$ & $11 / 64$ & $0 / 21$ & 19.0 & 17.2 & 0 \\
\hline Q1570 (cort21S) (100 and $50 \mu \mathrm{m})$ & $1 / 42$ & $16 / 183$ & $0 / 21$ & 2.4 & 8.7 & 0 \\
\hline Q1890 & $0 / 42$ & $2 / 64$ & $0 / 21$ & 0 & 3.1 & 0 \\
\hline Q2525 & $2 / 42$ & $2 / 64$ & $0 / 21$ & 4.8 & 3.1 & 0 \\
\hline Q3383 (100 and $50 \mu \mathrm{M})$ & $1 / 42$ & $0 / 182$ & $0 / 21$ & 2.4 & 0 & 0 \\
\hline Q3470 (50 $\mu \mathrm{M})$ & n.t. & $7 / 118$ & n.t. & n.t. & 5.9 & n.t. \\
\hline Q3910 & $3 / 42$ & $6 / 64$ & $0 / 21$ & 7.1 & 9.4 & 0 \\
\hline Q4765 (50 $\mu \mathrm{M})$ & $0 / 42$ & $1 / 64$ & $0 / 21$ & 0 & 1.6 & 0 \\
\hline Q5545 & $1 / 42$ & $8 / 64$ & $0 / 21$ & 2.4 & 12.5 & 0 \\
\hline ESP1 $(0.1 \mu \mathrm{m})$ & $3 / 166$ & $0 / 93$ & n.t. & 1.8 & 0 & n.t. \\
\hline rMUP1 $(0.1 \mu \mathrm{M})^{a}$ & $0 / 166$ & $0 / 93$ & n.t. & 0 & 0 & n.t. \\
\hline AAPDNRETF ( 1 and $0.1 \mu \mathrm{m}$ ) & $0 / 35$ & $0 / 104$ & n.t. & 0 & 0 & n.t. \\
\hline SYFPEITHI (1 and $0.1 \mu \mathrm{M})$ & $0 / 35$ & $0 / 104$ & n.t. & 0 & 0 & n.t. \\
\hline EEARSM $(0.1 \mu \mathrm{m})$ & n.t. & $0 / 93$ & n.t. & n.t. & 0 & n.t. \\
\hline Acetic acid & $0 / 35$ & n.t. & n.t. & 0 & n.t. & n.t. \\
\hline Arginine & $0 / 35$ & $0 / 93$ & n.t. & 0 & 0 & n.t. \\
\hline Aubepine & $0 / 69$ & $1 / 117$ & n.t. & 0 & 0.9 & n.t. \\
\hline Borneol & $0 / 69$ & $0 / 117$ & n.t. & 0 & 0 & n.t. \\
\hline Butanone & $0 / 69$ & $0 / 117$ & n.t. & 0 & 0 & n.t. \\
\hline Butyric acid & n.t. & $2 / 93$ & n.t. & n.t. & 2.2 & n.t. \\
\hline Butyrophenone & $0 / 69$ & $0 / 117$ & n.t. & 0 & 0 & n.t. \\
\hline$p$-Cresol & $0 / 69$ & $0 / 117$ & n.t. & 0 & 0 & n.t. \\
\hline Dimethyl disulfide & n.t. & $0 / 117$ & n.t. & n.t. & 0 & n.t. \\
\hline 2,5-Dimethylpyrazine & $0 / 69$ & $0 / 130$ & n.t. & 0 & 0 & n.t. \\
\hline Ethyl acetate & $0 / 69$ & $0 / 117$ & n.t. & 0 & 0 & n.t. \\
\hline Ethyl propionate & $0 / 69$ & $0 / 117$ & n.t. & 0 & 0 & n.t. \\
\hline Ethyl vanilline & $0 / 69$ & $0 / 117$ & n.t. & 0 & 0 & n.t. \\
\hline Eucalyptol & $0 / 69$ & $0 / 117$ & n.t. & 0 & 0 & n.t. \\
\hline$\beta$-Farnesene & $0 / 69$ & $0 / 119$ & n.t. & 0 & 0 & n.t. \\
\hline$\alpha$ - and $\beta$-Farnesene & $0 / 69$ & $0 / 117$ & n.t. & 0 & 0 & n.t. \\
\hline Fenchone & $0 / 69$ & $0 / 117$ & n.t. & 0 & 0 & n.t. \\
\hline Glutamic acid & $0 / 35$ & $0 / 106$ & n.t. & 0 & 0 & n.t. \\
\hline 2-Heptanone & $0 / 69$ & $0 / 130$ & n.t. & 0 & 0 & n.t. \\
\hline Indole & $0 / 69$ & $0 / 117$ & n.t. & 0 & 0 & n.t. \\
\hline Isoborneol & $0 / 69$ & $0 / 117$ & n.t. & 0 & 0 & n.t. \\
\hline Isobutylamine & $0 / 69$ & $0 / 130$ & n.t. & 0 & 0 & n.t. \\
\hline Isobutyric acid & n.t. & $0 / 93$ & n.t. & n.t. & 0 & n.t. \\
\hline Isovaleric acid & n.t. & $1 / 93$ & n.t. & n.t. & 1.1 & n.t. \\
\hline Methionine & $0 / 35$ & n.t. & n.t. & 0 & n.t. & n.t. \\
\hline Muscone & $0 / 69$ & $0 / 117$ & n.t. & 0 & 0 & n.t. \\
\hline Pentyl acetate & $0 / 69$ & $0 / 130$ & n.t. & 0 & 0 & n.t. \\
\hline Patchone & $0 / 69$ & $0 / 117$ & n.t. & 0 & 0 & n.t. \\
\hline Phenafleur & $0 / 69$ & $0 / 117$ & n.t. & 0 & 0 & n.t. \\
\hline Propionic acid & n.t. & $0 / 93$ & n.t. & n.t. & 0 & n.t. \\
\hline
\end{tabular}

The denominator in the responsive electrodes column indicates the number of recording sites on which the given ligand was tested; it includes only active electrodes that responded to at least one stimulus, including 100 -fold diluted urine and high potassium. The numerator indicates the number of these electrodes that responded to the specific ligand. Compounds in the first part of the table, labeled with a single letter followed by four digits, are sulfated steroids, except for the glucuronidated steroid Q3470 (supplemental Fig. S2, available at www.jneurosci.org as supplemental material). Nomenclature is from the Steraloids catalog. Compounds were tested at a concentration of $100 \mu \mathrm{m}$ except where indicated. n.t., Not tested. The references are as follows: AAPDNRETF, SYFPEITHI (Leinders-Zufall et al., 2004); EEARSM (Mucignat-Caretta et al., 1995); ESP1 (Kimoto et al., 2005), rMUP1 (Chamero et al., 2007); acetic acid, butyric acid, propionic acid, isobutyric acid, isovaleric acid (Michael et al., 1971); pentyl acetate (Novotny et al., 1986; Leinders-Zufall et al., 2000; Punta et al., 2002); 2-heptanone (Novotny et al., 1986; Jemiolo et al., 1989; Leinders-Zufall et al., 2000; Sam et al., 2001; Boschat et al., 2002; Punta et al., 2002; Trinh and Storm, 2003); isobutylamine (Punta et al., 2002); 2,5-dimethylpyrazine (Novotny et al., 1986; Leinders-Zufall et al., 2000; Sam et al., 2001; Punta et al., 2002; Trinh and Storm, 2003); $\alpha$ and $\beta$ farnesenes (Novotny et al., 1990, 1999; Ma et al., 1999; Leinders-Zufall et al., 2000; Sam et al., 2001; Punta et al., 2002); dimethyl disulfide (Singer et al., 1976); arginine, methionine, glutamate, indole, muscone, patchone, $p$-cresol, eucalyptol, fenchone, borneol, isoborneol, aubepine, butyrophenone, phenafleur (Sam et al., 2001); ethyl acetate, ethyl propionate, ethyl vanilline, butanone (Trinh and Storm, 2003).

${ }^{a}$ Note that responses reported by Chamero et al. (2007) occurred at concentrations $>0.1 \mu \mathrm{m}$. 
A

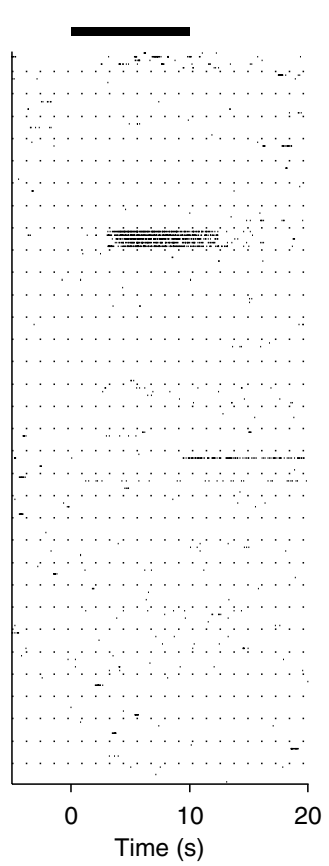

C

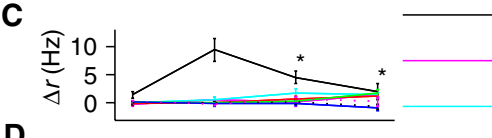

D
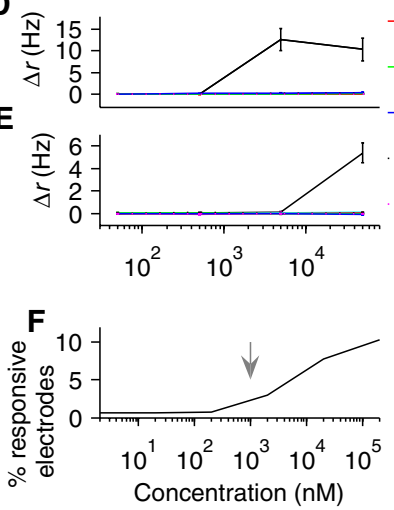

B

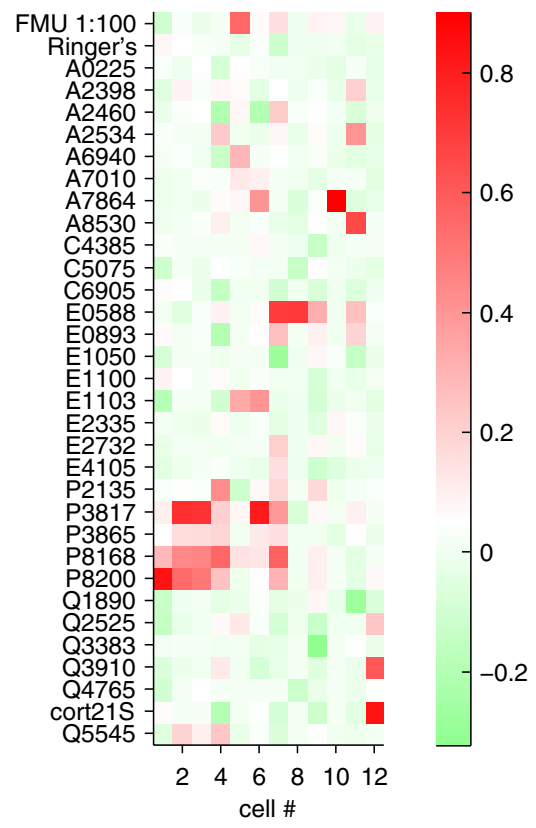

cort21S

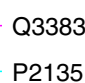

P2135

P3865

A6940

A7010

E4105

Q3470
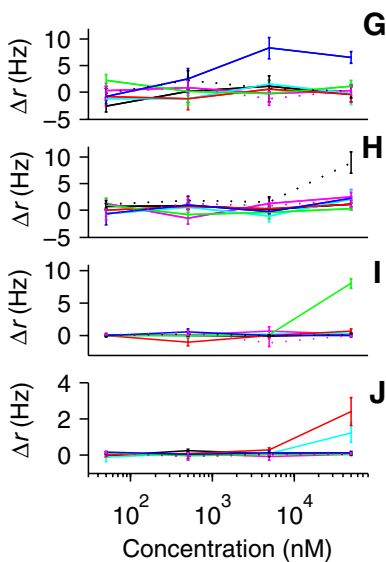

Concentration (nM)

Figure 6. VSNs are highly selective. $A$, Raster plot of firing responses of one VSN to a panel of 31 sulfated steroids. The

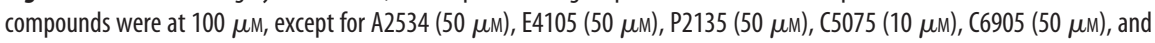
Q4765 (50 $\mu \mathrm{m})$. Each row represents a single trial (shown grouped by stimulus, but trials to different stimuli were interleaved; 5 trials total). For this neuron, only one synthetic compound excited a reliable spiking response. The black bar represents the stimulus timing. $\boldsymbol{B}$, Twelve single-unit response profiles to 31 sulfated steroids as in $\boldsymbol{A}$. Normalized responses (see Materials and Methods) are shown as a color scale. The 10th neuron is shown in $\boldsymbol{A} . \mathbf{C}-\boldsymbol{E}, \mathbf{G}-\boldsymbol{J}$, Dose/response profiles of seven single units to a set of eight structurally related compounds. Most units responded to only one of these ligands, with $\mathrm{EC}_{50}$ typically in the micromolar range. The points in $C$ marked with asterisks underestimate the real $\Delta r$ because at those ligand concentrations the spike amplitude decreased during prolonged high firing rates to the point at which they could not be sorted. $\boldsymbol{F}$, The percentage of electrodes that respond to cort21S increases as the concentration of cort21S rises. The arrow indicates the estimated concentration of cort $21 \mathrm{~S}$ in female mouse urine.

ied widely by compound, the overall percentages were quite similar between males and females (Table 1). A bootstrap analysis, performed by comparing the aggregate differences between the sexes with datasets in which the sexes of the recorded animals had been scrambled, revealed no significant difference ( $p=0.45$ ) in detection between males and females. This is consistent with results from in situ hybridization studies, which have not found significant differences in receptor expression between males and females (Firestein, 2001). However, our data do not rule out the possibility of differences in the detection abilities of males and females for stimuli not tested here or of more subtle differences in the percentages of responsive neurons between the sexes.

\section{Detection of sulfated steroids depends on TRPC2}

The VSN response to urine depends on the ion channel TRPC2 (Stowers et al., 2002). We therefore tested whether the VSN response to sulfated steroids also requires TRPC2. Although TRPC2 males displayed responses to high potassium, no responses to any of 30 synthetic sulfated steroids, including cort21S, were found (Table 1). By bootstrap randomization of genotype, this difference is significant $(p<0.05)$.

\section{Sulfated steroids isolated from female mouse urine are not detected in male mouse urine}

Sulfated steroids were isolated in the urine of $\mathrm{BALB} / \mathrm{c}$ females. To determine whether these compounds are expressed in a sexspecific manner, extracts from urine of $\mathrm{BALB} / \mathrm{c}$ male mice were analyzed similarly. Such compounds were not detectable in the urine of male mice, indicating that these compounds are quite female specific (Fig. 7A, inset). This result was obtained for three separate purifications and analyses of male and female mouse urine.

\section{Urine expression of glucocorticoid sulfates is increased by stress}

Sulfated steroids in urine could arise from metabolism of steroid hormones, a family of compounds that play a central role in the control of an animal's physiological status, reproductive ability, and behavior (Larsen and Williams, 2003). Consequently, the olfactory ability to detect and measure concentrations of steroid metabolites in urine could confer direct knowledge about physiological status of the donor. In particular, the structure of cort21S suggests a possible origin as a metabolite of corticosterone, a major regulator of arousal and stress in rodents (Larsen and Williams, 2003).

To test whether cort21S correlates with physiological status, we quantified urine concentrations of cort21S both before and after a period of restraint stress (see Materials and Methods), a condition shown to elevate serum levels of corticosterone (Boyle et al., 2006). Compared with unstressed controls, stressed animals displayed an approximately threefold elevation of both cort21S and SS427, along with a somewhat smaller elevation in SS429 (Fig. 7B). Thus, the concentrations of cort21S and SS427 in urine reflect the physiological status of the animal.

\section{Discussion}

\section{The accessory olfactory system}

The mammalian accessory olfactory (or vomeronasal) system has long been thought to serve a specialized role in olfaction (Scalia 


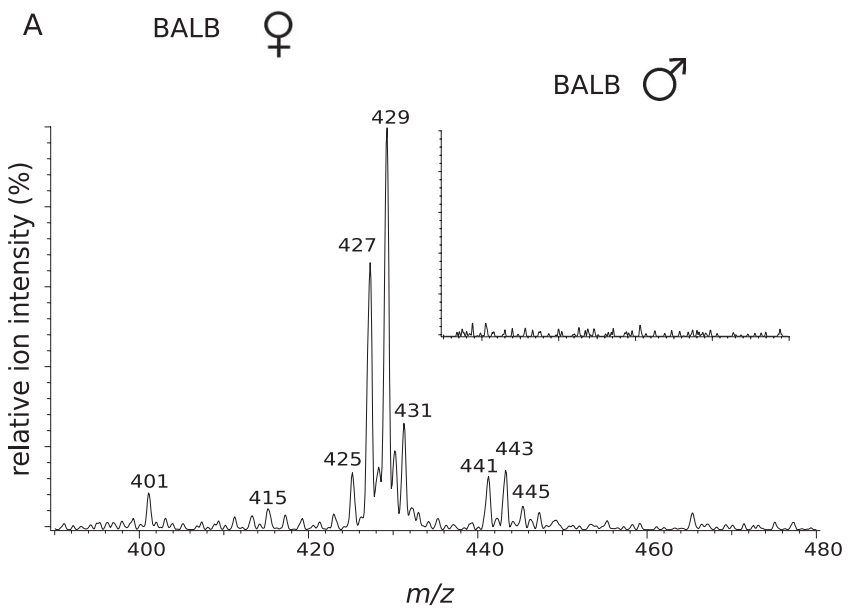

B

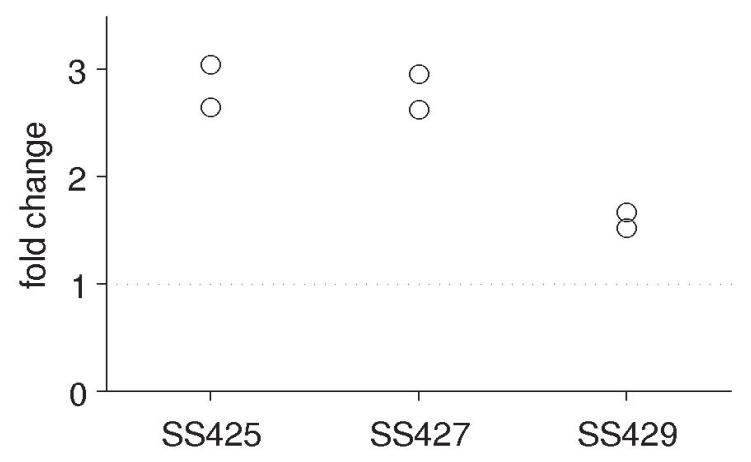

Figure 7. Expression of and behavioral responses to sulfated steroids. $A, E S / / M S / M S$ precursors of sulfate ions $(\mathrm{m} / \mathrm{z} 97)$ in female mouse urine of the $B A L B / c$ strain. Inset shows corresponding result for male mouse urine, normalized to the size of the $m / z 429$ peak in female urine. $\boldsymbol{B}$, The relative changes in $\$ \$ 425, S \$ 427$, and $\$ \$ 429$ after restraint stress compared with unstressed controls are shown in two separate replicates. SS425 and SS427 increased by a consistent threefold after restraint stress. Pooling across all compounds, the elevation in SS levels after restraint stress is statistically significant ( $p<0.01$, rank-sum test).

and Winans, 1975), serving to detect and recognize pheromones, compounds essential for social communication (Brennan and Zufall, 2006). The accessory olfactory system does not have a monopoly on the detection of such cues, because the main olfactory system also plays an important role. Nevertheless, the thesis that the accessory olfactory system is specialized for the detection of social odors has received considerable experimental support (Wysocki and Lepri, 1991; Halpern and Martínez-Marcos, 2003; Leypold et al., 2002; Stowers et al., 2002; Chamero et al., 2007; Kimchi et al., 2007).

The accessory olfactory system expresses two large families of receptor types, V1R and V2R, with $\sim 250$ different types in mouse (Dulac and Torello, 2003; Halpern and Martínez-Marcos, 2003; Shi and Zhang, 2007). With the exception of the widely coexpressed V2R2 receptors (Martini et al., 2001), each VSN apparently expresses just one receptor type (Dulac and Torello, 2003). Both in terms of size and sequence, these families are highly divergent among different vertebrates (Shi and Zhang, 2007).

\section{Detection of sulfated steroids by VSNs}

We have shown that a wide variety of sulfated steroids are detected by VSNs. These compounds caused significant increases in the firing rates of VSNs. Consistent with previous results using whole urine (Holy et al., 2000), we have not yet observed any clear examples of inhibitory responses to these compounds.

Although sulfated steroids have not been reported previously to activate VSNs or act as a pheromone in mice or any other tetrapods, both goldfish (Sorensen et al., 1995) and lampreys (Sorensen et al., 2005) use sulfated steroids as pheromones, albeit not of the glucocorticoid family identified in this work. Although the responsive receptor(s) in these aquatic species is not known, both anatomical similarities (Dulka, 1993) and molecular homologies (Saraiva and Korsching, 2007; Shi and Zhang, 2007) with the mammalian vomeronasal system have been identified in teleost fish. Thus, it seems possible that the olfactory detection of steroid metabolites is an ancestral vertebrate characteristic.

\section{Selectivity of VSNs for sulfated steroids}

Collectively, VSNs responded to all tested families of sulfated steroids, including the androstan-, androsten-, cholestan-, estratrien-, pregnan-, and pregnen- families. Thus, VSNs are capable of detecting sulfated derivatives of all the major classes of steroid hormones that control mammalian physiology.

Complementing this collective breadth of detection, our results show that individual VSNs are highly selective. Among the compounds we have tested, single VSNs responded to just one or a few compounds with close structural similarity. Because different compounds generally excite different neural populations, this selectivity endows the accessory olfactory system with the possibility of considerable specificity.

In extracts of female mouse urine, $80 \%$ of the total aggregate neural response was sensitive to treatment by sulfatase, indicating (in conjunction with other results) that sulfated steroids account for the large majority of the activity triggered by this stimulus (Fig. 5B). Moreover, although we were able to confirm the activity of some previously reported VSN ligands (ESP1) (Kimoto et al., 2005, 2007), we found that collectively these other ligands excited far less activity than many single sulfated steroids (Fig. $5 D-I$, Table 1). In particular, consistent with some previous reports (Luo et al., 2003), we find little evidence for widespread activation of VSNs by volatiles, for either "conventional odorants" or ones that were identified from natural sources. [Our data do not strictly exclude any role for volatiles; in particular, it remains possible that the small amount of activity lost during extraction (Fig. 1) could in part be attributable to volatiles.] It is possible that there were cells that responded to some of these ligands, but that they were not recorded by the MEA. However, evidence suggests that the MEA records from both V1R and V2R cell populations (Kimoto et al., 2007; Holekamp et al., 2008). Although sulfated steroids account for the majority of activity in female mouse urine, ligands from other natural sources also activate VSNs (Kimoto et al., 2007).

\section{Sex- and strain-specific expression of sulfated steroids}

Among mice of the BALB/c strain, we find that females, but apparently not males, express sulfated steroids in their urine (Fig. $7 A$ ). We cannot strictly exclude the possibility that low levels of sulfated steroids might have been present in male mouse urine without producing an ion of $m / z 97$, because detectability by MS can be suppressed by other ions (Annesley, 2003) and our comparative analysis used whole extracts. In future work, this issue can be examined in more detail by performing comparable complete purifications and analyses of male mouse urine. However, our data provide strong support for a large, and perhaps absolute, sex bias in urine expression of sulfated steroids. Our result is consistent with a previous report that sulfation of exogenously 
supplied radiolabeled steroids was only detected in the urine of females (Lewis, 1969) and another showing that the expression of some sulfotransferases is female specific (Alnouti and Klaassen, 2006).

\section{Sulfation of steroids: implications for physiology and signaling}

During sulfation, steroids become dramatically more soluble in aqueous solution while simultaneously prevented from diffusing across cell membranes and binding to the classical cytoplasmic steroid receptors. For this reason, sulfation has been viewed as a mechanism to inactivate steroids and to facilitate their clearance from the body (Larsen and Williams, 2003). For example, in response to restraint stress plasma corticosterone levels rise $\sim 10$ fold over $\sim 15 \mathrm{~min}$ and then fall again over $\sim 2 \mathrm{~h}$ (Boyle et al., 2006). Our data show a complementary threefold rise in urinary cort $21 \mathrm{~S}$ averaged over a span of $4 \mathrm{~h}$ after brief restraint stress (Fig. $7 B$ ), consistent with the clearance of corticosterone from the body. Thus, the presence and concentration of sulfated steroids in urine reflects the recent history of steroid production in the body.

Intriguingly, our data also suggest that the detection of sulfated steroids by VSNs may be well matched to their expression in urine. We find that urinary cort $21 \mathrm{~S}$ is at concentrations near $1 \mu \mathrm{M}$ under basal conditions and rises several-fold after restraint stress. Correspondingly, many of the VSNs that detected cort21S (Figs. $4,6)$ had an $\mathrm{EC}_{50}$ also near $1 \mu \mathrm{M}$ and might therefore be well within their dynamic range for encoding such a concentration increase. We also note that the presence of other receptor cells with both lower and higher affinities (Fig. $6 \mathrm{C}$, where the $\mathrm{EC}_{50}$ is between 50 and $500 \mathrm{~nm}$ ) ensures that concentration changes could be robustly detected over much more than a 10 -fold range. Indeed, the percentage of electrodes that recorded responses to cort21S rose with concentration, with a particularly sharp increase at concentrations higher than a few hundred nanomolar (Fig. $6 F$ ). Together, these observations suggest that cort21S may be detected by more than one vomeronasal receptor type. Vomeronasal cort $21 \mathrm{~S}$ receptors thus appear to mirror the intracellular mineral corticoid and glucocorticoid receptors in having widely separated thresholds for detection of a single ligand (Oitzl et al., 1995; De Kloet et al., 1998). It is an intriguing question whether vomeronasal receptors with different affinities might serve different functions.

We propose that the ability to detect and measure concentrations of steroid metabolites in urine confers direct knowledge about the sex and physiological status of the donor. Although socially relevant cues have long been known to be detected by vomeronasal neurons (Dulac and Torello, 2003; Halpern and Martínez-Marcos, 2003), the connection to particular ligands has been elusive. Because of their role in controlling physiology, steroids and their metabolites may represent an "honest" signal ( $\mathrm{Za}$ havi, 1975; Guilford, 1995), one that cannot be readily altered to achieve reproductive advantages.

\section{References}

Alnouti Y, Klaassen CD (2006) Tissue distribution and ontogeny of sulfotransferase enzymes in mice. Toxicol Sci 93:242-255.

Annesley TM (2003) Ion suppression in mass spectrometry. Clin Chem 49:1041-1044.

Boschat C, Pélofi C, Randin O, Roppolo D, Luscher C, Broillet MC, Rodriguez I (2002) Pheromone detection mediated by a V1r vomeronasal receptor. Nat Neurosci 5:1261-1262.

Boyle MP, Kolber BJ, Vogt SK, Wozniak DF, Muglia LJ (2006) Forebrain glucocorticoid receptors modulate anxiety-associated locomotor activation and adrenal responsiveness. J Neurosci 26:1971-1978.

Brennan PA, Kendrick KM (2006) Mammalian social odours: attraction and individual recognition. Philos Trans $\mathrm{R}$ Soc Lond B Biol Sci 361:2061-2078.

Brennan PA, Zufall F (2006) Pheromonal communication in vertebrates. Nature 444:308-315.

Brunet LJ, Gold GH, Ngai J (1996) General anosmia caused by a targeted disruption of the mouse olfactory cyclic nucleotide-gated cation channel. Neuron 17:681-693.

Chamero P, Marton TF, Logan DW, Flanagan K, Cruz JR, Saghatelian A, Cravatt BF, Stowers L (2007) Identification of protein pheromones that promote aggressive behaviour. Nature 450:899-902.

De Kloet ER, Vreugdenhil E, Oitzl MS, Joëls M (1998) Brain corticosteroid receptor balance in health and disease. Endocr Rev 19:269-301.

Del Punta K, Leinders-Zufall T, Rodriguez I, Jukam D, Wysocki CJ, Ogawa S, Zufall F, Mombaerts P (2002) Deficient pheromone responses in mice lacking a cluster of vomeronasal receptor genes. Nature 419:70-74.

Dulac C, Torello AT (2003) Molecular detection of pheromone signals in mammals: from genes to behaviour. Nat Rev Neurosci 4:551-562.

Dulka JG (1993) Sex pheromone systems in goldfish: comparisons to vomeronasal systems in tetrapods. Brain Behav Evol 42:265-280.

Firestein S (2001) How the olfactory system makes sense of scents. Nature 413:211-218.

Guilford T (1995) Animal signals: all honesty and light? Trends Ecol Evol 10:100-101.

Halpern M, Martínez-Marcos A (2003) Structure and function of the vomeronasal system: an update. Prog Neurobiol 70:245-318.

Holekamp TF, Turaga D, Holy TE (2008) Fast three-dimensional fluorescence imaging of activity in neural populations by objective-coupled planar illumination microscopy. Neuron 57:661-672.

Holy TE, Dulac C, Meister M (2000) Responses of vomeronasal neurons to natural stimuli. Science 289:1569-1572.

Hudson R, Distel H (1986) Pheromonal release of suckling in rabbits does not depend on the vomeronasal organ. Physiol Behav 37:123-128.

Jemiolo B, Andreolini F, Xie TM, Wiesler D, Novotny M (1989) Pubertyaffecting synthetic analogs of urinary chemosignals in the house mouse, Mus domesticus. Physiol Behav 46:293-298.

Kimchi T, Xu J, Dulac C (2007) A functional circuit underlying male sexual behaviour in the female mouse brain. Nature 448:1009-1014.

Kimoto H, Haga S, Sato K, Touhara K (2005) Sex-specific peptides from exocrine glands stimulate mouse vomeronasal sensory neurons. Nature 437:898-901.

Kimoto H, Sato K, Nodari F, Haga S, Holy TE, Touhara K (2007) Sex- and strain-specific expression and vomeronasal activity of mouse ESP family peptides. Curr Biol 17:1879-1884.

Larsen PR, Williams RH, eds (2003) Williams textbook of endocrinology, Ed 10. Philadelphia: Saunders.

Leinders-Zufall T, Lane AP, Puche AC, Ma W, Novotny MV, Shipley MT, Zufall F (2000) Ultrasensitive pheromone detection by mammalian vomeronasal neurons. Nature 405:792-796.

Leinders-Zufall T, Brennan P, Widmayer P, S PC, Maul-Pavicic A, Jäger M, Li XH, Breer H, Zufall F, Boehm T (2004) MHC class I peptides as chemosensory signals in the vomeronasal organ. Science 306:1033-1037.

Lewis DA (1969) Androgen sulphate formation in male and female mice. Biochem J 115:489-493.

Leypold BG, Yu CR, Leinders-Zufall T, Kim MM, Zufall F, Axel R (2002) Altered sexual and social behaviors in trp2 mutant mice. Proc Natl Acad Sci USA 99:6376-6381.

Lin DY, Zhang SZ, Block E, Katz LC (2005) Encoding social signals in the mouse main olfactory bulb. Nature 434:470-477.

Luo M, Fee MS, Katz LC (2003) Encoding pheromonal signals in the accessory olfactory bulb of behaving mice. Science 299:1196-1201.

Ma W, Miao Z, Novotny MV (1999) Induction of estrus in grouped female mice (Mus domesticus) by synthetic analogues of preputial gland constituents. Chem Senses 24:289-293.

Martini S, Silvotti L, Shirazi A, Ryba NJ, Tirindelli R (2001) Co-expression of putative pheromone receptors in the sensory neurons of the vomeronasal organ. J Neurosci 21:843-848.

Michael RP, Keverne EB, Bonsall RW (1971) Pheromones: isolation of male sex attractants from a female primate. Science 172:964-966.

Mucignat-Caretta C, Caretta A, Cavaggioni A (1995) Acceleration of pu- 
berty onset in female mice by male urinary proteins. J Physiol (Lond) 486:517-522.

Novotny M, Jemiolo B, Harvey S, Wiesler D, Marchlewska-Koj A (1986) Adrenal-mediated endogenous metabolites inhibit puberty in female mice. Science 231:722-725.

Novotny M, Harvey S, Jemiolo B (1990) Chemistry of male dominance in the house mouse, Mus domesticus. Experientia 46:109-113.

Novotny MV, Ma W, Wiesler D, Zidek L (1999) Positive identification of the puberty-accelerating pheromone of the house mouse: the volatile ligands associating with the major urinary protein. Proc Biol Sci 266:2017-2022.

Oitzl MS, van Haarst AD, Sutanto W, de Kloet ER (1995) Corticosterone, brain mineralocorticoid receptors (MRs) and the activity of the hypothalamic-pituitary-adrenal (HPA) axis: the Lewis rat as an example of increased central MR capacity and a hyporesponsive HPA axis. Psychoneuroendocrinology 20:655-675.

Sam M, Vora S, Malnic B, Ma W, Novotny MV, Buck LB (2001) Odorants may arouse instinctive behaviours. Nature 412:142.

Saraiva LR, Korsching SI (2007) A novel olfactory receptor gene family in teleost fish. Genome Res 17:1448-1457.

Scalia F, Winans SS (1975) The differential projections of the olfactory bulb and accessory olfactory bulb in mammals. J Comp Neurol 161:31-55.

Schaal B, Coureaud G, Langlois D, Giniès C, Sémon E, Perrier G (2003) Chemical and behavioural characterization of the rabbit mammary pheromone. Nature 424:68-72.

Segev R, Goodhouse J, Puchalla J, Berry 2nd MJ (2004) Recording spikes from a large fraction of the ganglion cells in a retinal patch. Nat Neurosci 7:1154-1161

Shi P, Zhang J (2007) Comparative genomic analysis identifies an evolutionary shift of vomeronasal receptor gene repertoires in the vertebrate transition from water to land. Genome Res 17:166-174.

Singer AG, Agosta WC, O'Connell RJ, Pfaffmann C, Bowen DV, Field FH (1976) Dimethyl disulfide: an attractant pheromone in hamster vaginal secretion. Science 191:948-950.

Sorensen PW, Scott AP, Stacey NE, Bowdin L (1995) Sulfated 17,20 betadihydroxy-4-pregnen-3-one functions as a potent and specific olfactory stimulant with pheromonal actions in the goldfish. Gen Comp Endocrinol 100:128-142.

Sorensen PW, Fine JM, Dvornikovs V, Jeffrey CS, Shao F, Wang J, Vrieze LA, Anderson KR, Hoye TR (2005) Mixture of new sulfated steroids functions as a migratory pheromone in the sea lamprey. Nat Chem Biol $1: 324-328$.

Stowers L, Holy TE, Meister M, Dulac C, Koentges G (2002) Loss of sex discrimination and male-male aggression in mice deficient for TRP2. Science 295:1493-1500.

Trinh K, Storm D (2003) Vomeronasal organ detects odorants in absence of signaling through main olfactory epithelium. Nat Neurosci 6:519-525.

Wyatt TD (2003) Pheromones and animal behaviour. Cambridge, UK: Cambridge UP.

Wysocki CJ, Lepri JJ (1991) Consequences of removing the vomeronasal organ. J Steroid Biochem Mol Biol 39:661-669.

Zahavi A (1975) Mate selection-a selection for a handicap. J Theor Biol 53:205-214. 